\title{
Front Matter: Volume 8940
}

, "Front Matter: Volume 8940," Proc. SPIE 8940, Optical Biopsy XII, 894001 (28 March 2014); doi: 10.1117/12.2052737

SPIE. Event: SPIE BiOS, 2014, San Francisco, California, United States 


\section{PROGRESS IN BIOMEDICAL OPTICS AND IMAGING}

\section{Optical Biopsy XII}

Robert R. Alfano

Stavros G. Demos

Editors

\section{4-5 February 2014 \\ San Francisco, California, United States}

Sponsored by

SPIE

Cosponsored by

BaySpec, Inc. (United States)

Energy Research Company (United States)

Hamamatsu Corporation

PerkinElmer Inc. (United States)

Intuitive Surgical, Inc. (United States)

Supercontinuum Anniversary Sponsors

Coherent Inc.

Corning Inc. (United States)

Fianium Ltd. (United Kingdom)

LEUKOS (France)

NKT Photonics A/S (Denmark)

ThorLabs, Inc.

Published by

SPIE 
The papers included in this volume were part of the technical conference cited on the cover and title page. Papers were selected and subject to review by the editors and conference program committee. Some conference presentations may not be available for publication. The papers published in these proceedings reflect the work and thoughts of the authors and are published herein as submitted. The publisher is not responsible for the validity of the information or for any outcomes resulting from reliance thereon.

Please use the following format to cite material from this book:

Author(s), "Title of Paper," in Optical Biopsy XII, edited by Robert R. Alfano, Stavros G. Demos, Proceedings of SPIE Vol. 8940 (SPIE, Bellingham, WA, 2014) Article CID Number.

ISSN: 1605-7422

ISBN: 9780819498533

Published by

SPIE

P.O. Box 10, Bellingham, Washington 98227-0010 USA

Telephone +1 3606763290 (Pacific Time) · Fax +1 3606471445

SPIE.org

Copyright $@ 2014$, Society of Photo-Optical Instrumentation Engineers.

Copying of material in this book for internal or personal use, or for the internal or personal use of specific clients, beyond the fair use provisions granted by the U.S. Copyright Law is authorized by SPIE subject to payment of copying fees. The Transactional Reporting Service base fee for this volume is $\$ 18.00$ per article (or portion thereof), which should be paid directly to the Copyright Clearance Center (CCC), 222 Rosewood Drive, Danvers, MA 01923. Payment may also be made electronically through CCC Online at copyright.com. Other copying for republication, resale, advertising or promotion, or any form of systematic or multiple reproduction of any material in this book is prohibited except with permission in writing from the publisher. The CCC fee code is $1605-7422 / 14 / \$ 18.00$.

Printed in the United States of America.

Publication of record for individual papers is online in the SPIE Digital Library.

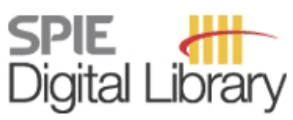

SPIEDigitalLibrary.org

Paper Numbering: Proceedings of SPIE follow an e-First publication model, with papers published first online and then in print and on CD-ROM. Papers are published as they are submitted and meet publication criteria. A unique, consistent, permanent citation identifier (CID) number is assigned to each article at the time of the first publication. Utilization of CIDs allows articles to be fully citable as soon as they are published online, and connects the same identifier to all online, print, and electronic versions of the publication. SPIE uses a six-digit CID article numbering system in which:

- The first four digits correspond to the SPIE volume number.

- The last two digits indicate publication order within the volume using a Base 36 numbering

system employing both numerals and letters. These two-number sets start with 00, 01, 02, 03, 04,

05, 06, 07, 08, 09, 0A, OB ... 0Z, followed by 10-1Z, 20-2Z, etc.

The CID Number appears on each page of the manuscript. The complete citation is used on the first page, and an abbreviated version on subsequent pages. Numbers in the index correspond to the last two digits of the six-digit CID Number. 


\section{Contents}

vii Conference Committee

ix Introduction

xi Anniversary Session: 45 Years of Supercontinuum Generation Abstracts

xiii Anniversary Session: 45 Years of Supercontinuum Generation Slide Presentation:

Ultimate ultrafast white light's first observations: early discovery circa 1970 [8940-32]

Robert R. Alfano, The City College of New York (United States)

Diffuse Optical Methods for Assessing Breast Cancer Chemotherapy (Hot Topics Presentation, Presentation Video) [8940-57]

B. Tromberg, Beckman Laser Institute and Medical Clinic (United States)

View the presentation on the SPIE Digital Library: http://dx.doi.org/10.1117/12.2064489

\section{SESSION 1 LIGHT SCATTERING METHODS}

894006 Propagation and scattering of vector light beam in turbid scattering medium [8940-5] A. Doronin, Univ. of Otago (New Zealand); G. Milione, The City College of New York (United States); I. Meglinski, Univ. of Otago (New Zealand); R. R. Alfano, The City College of New York (United States)

894007 Diffusing-wave polarimetry for tissue diagnostics [8940-6]

C. Macdonald, A. Doronin, A. F. Peña, The Jack Dodd Ctr. for Quantum Technology, Univ. of Otago (New Zealand); M. Eccles, Dunedin School of Medicine, Univ. of Otago (New Zealand); I. Meglinski, The Jack Dodd Ctr. for Quantum Technology, Univ. of Otago (New Zealand)

\section{SESSION 2 MICROSCOPY METHODS}

8940 0A Automated cellular pathology in noninvasive confocal microscopy [8940-9] M. Ting, The Rockefeller Univ. (United States) and High Technology High School (United States); J. Krueger, D. Gareau, The Rockefeller Univ. (United States)

\section{SESSION $3 \quad$ RAMAN SCATTERING METHODS}

8940 0C Brain metastasis detection by resonant Raman optical biopsy method [8940-11]

Y. Zhou, The General Hospital of the Air Force, PLA (China); C. Liu, The City College of the City Univ. of New York (United States); G. Cheng, The General Hospital of the Air Force, PLA (China); L. Zhou, Beijing Cancer Hospital (China); C. Zhang, Y. Pu, The City College of the City Univ. of New York (United States); Z. Li, Beijing Cancer Hospital (China); Y. Liu, Institute of Physics (China); Q. Li, W. Wang, Beihang Univ. (China); R. R. Alfano, The City College of the City Univ. of New York (United States) 
8940 OD Raman microspectroscopic study of oral buccal mucosa [8940-12]

I. Behl, Advanced Ctr. for Treatment, Research \& Education in Cancer (India);

H. Mamgain, WITec GmbH (Germany); A. Deshmukh, L. Kukreja, A. R. Hole, C. M. Krishna,

Advanced Ctr. for Treatment, Research \& Education in Cancer (India)

8940 OE In vivo Raman spectroscopy of cervix cancers [8940-13]

S. Rubina, P. Sathe, T. K. Dora, S. Chopra, Advanced Ctr. for Treatment, Research \& Education in Cancer (India); A. Maheshwari, Tata Memorial Hospital (India); C. M. Krishna, Advanced Ctr. for Treatment, Research \& Education in Cancer (India)

\section{SESSION 4 FLUORESCENCE METHODS}

$8940 \mathrm{OH}$ Autofluorescence lifetime metrology for label-free detection of cartilage matrix degradation [8940-16]

M. B. Nickdel, Univ. of Oxford (United Kingdom); J. L. Lagarto, D. J. Kelly, H. B. Manning, Imperial College London (United Kingdom); K. Yamamoto, Univ. of Oxford (United Kingdom); C. B. Talbot, C. Dunsby, P. French, Imperial College London (United Kingdom); Y. Itoh, Univ. of Oxford (United Kingdom)

8940 OL Noninvasive diagnosis of oral cancer by Stokes shift spectroscopy [8940-20]

J. Ebenezar, Jamal Mohamed College (India); S. Ganesan, P. Aruna, Anna Univ. Chennai (India); R. Muralinaidu, Rajah Muthiah Dental College and Hospital, Annamalai Univ. (India)

\section{SESSION $5 \quad$ NOVEL METHODS AND INSTRUMENTATION I}

894000 Wavelength-dependent measurement of contrast in NIR and extended NIR spectral range $(650-1600 \mathrm{~nm})$ in phantoms [8940-23]

D. Salo, D. M. Kim, M. Y. Berezin, Washington Univ. School of Medicine in St. Lovis (United States)

8940 OP Parametric study of different contributors to tumor thermal profile [8940-24] M. Tepper, I. Gannot, Tel Aviv Univ. (Israel)

$89400 Q \quad$ Optical characterization of ex-vivo axillary lymph nodes of breast-cancer patients using a custom-built spectrophotometer [8940-25]

A. Sampathkumar, F.L. Lizzi Ctr. for Biomedical Engineering, Riverside Research Institute (United States); E. Saegusa-Beecroft, Univ. of Hawai'i (United States) and Kuakani Medical Ctr. (United States); J. Mamou, P. V. Chitnis, F.L. Lizzi Ctr. for Biomedical Engineering, Riverside Research Institute (United States); J. Machi, Univ. of Hawaili (United States) and Kuakani Medical Ctr. (United States); E. J. Feleppa, F.L. Lizzi Ctr. for Biomedical Engineering, Riverside Research Institute (United States)

8940 OR Enhanced visualization of the bile duct via parallel white light and indocyanine green fluorescence laparoscopic imaging [8940-26]

S. G. Demos, Lawrence Livermore National Lab. (United States); S. Urayama, Davis Medical Ctr., Univ. of California (United States) 
8940 OU Measurement of fluorescent probes concentration ratio in the cerebrospinal fluid for early detection of Alzheimer's disease [8940-29]

O. Harbater, I. Gannot, Tel Aviv Univ. (Israel)

8940 OV Third therapeutic spectral window for deep tissue imaging [8940-30]

L. A. Sordillo, The City College of the City Univ. of New York (United States); S. Pratavieira, Univ. de São Paulo (Brazil); Y. Pu, K. Salas-Ramirez, L. Shi, L. Zhang, Y. Budansky, R. R. Alfano, The City College of the City Univ. of New York (United States)

\section{SESSION 7 ANNIVERSARY SESSION: 45 YEARS OF SUPERCONTINUUM GENERATION}

894011 Supercontinuum generation in microstructure fiber at the advent of femtosecond combs (Invited Paper) [8940-36]

S. T. Cundiff, JILA (United States)

894013 Cross-phase modulation in optical Kerr media: review of discovery experiments (Invited Paper) [8940-38]

P. L. Baldeck, Lab. Interdisciplinaire de Physique, CNRS, Univ. Joseph Fourier (France)

\section{POSTER SESSION}

894014 Tumor margin detection using optical biopsy techniques [8940-42]

Y. Zhou, The General Hospital of the Air Force, PLA (China); C. Liu, The City College of the City Univ. New York (United States); J. Li, Z. Li, L. Zhou, K. Chen, Beijing Cancer Hospital (China); Y. Pu, The City College of the City Univ. of New York (United States); Y. He, Beijing Normal Univ. (China); K. Zhu, Institute of Physics (China); Q. Li, Beihang Univ. (China); R. R. Alfano, The City College of the City Univ. of New York (United States)

894015 Tryptophan content for monitoring breast cancer cell aggressiveness by native fluorescence spectroscopy [8940-41]

L. Zhang, Y. Pu, The City College of the City Univ. of New York (United States); J. Xue, Washington Univ. in St. Louis, School of Medicine (United States); S. Pratavieira, The City College of the City Univ. of New York (United States) and Univ. de São Paulo (Brazil); B. Xu, S. Achilefu, Washington Univ. in St. Louis, School of Medicine (United States); R. R. Alfano, The City College of the City Univ. of New York (United States)

894016 Grading of cervical intraepithelial neoplasia using spatial frequency for optical histology [8940-40]

Y. Pu, The City College of the City Univ. of New York (United States); J. Jagtap, A. Pradhan, Indian Institute of Technology Kanpur (India); R. R. Alfano, The City College of the City Univ. of New York (United States)

894017 Enhancing the depth of tissue microscope imaging using two-photon excitation of the second singlet state of fluorescent agents [8940-39]

Y. Pu, L. Shi, The City College of New York (United States); S. Pratavieira, The City College of New York (United States) and Univ. de São Paulo (Brazil); R. R. Alfano, The City College of New York (United States) 


\section{HOT TOPICS SESSION}

894018 Diffuse optical methods for assessing breast cancer chemotherapy [8940-57]

B. J. Tromberg, Beckman Laser Institute and Medical Clinic (United States)

Author Index

vi

Proc. of SPIE Vol. $8940894001-6$

Downloaded From: https://www.spiedigitallibrary.org/conference-proceedings-of-spie on 26 Apr 2023 Terms of Use: https://www.spiedigitallibrary.org/terms-of-use 


\section{Conference Committee}

Symposium Chairs

James G. Fujimoto, Massachusetts Institute of Technology (United States)

R. Rox Anderson, Wellman Center for Photomedicine, Massachusetts General Hospital (United States) and Harvard School of Medicine (United States)

Program Track Chairs

Tuan Vo-Dinh, Fitzpatrick Institute for Photonics, Duke University (United States)

Anita Mahadevan-Jansen, Vanderbilt University (United States)

Conference Chairs

Robert R. Alfano, The City College of New York (United States)

Stavros G. Demos, Lawrence Livermore National Laboratory

(United States)

Conference Program Committee

Irving J. Bigio, Boston University (United States)

Nicole J. Crane, Naval Medical Research Center (United States)

Zhiwei Huang, National University of Singapore (Singapore)

Amir Gandjbakhche, National Institutes of Health (United States)

Israel Gannot, Tel Aviv University (Israel)

Xiaohui Ni, Harvard University (United States)

Milind Rajadhyaksha, Memorial Sloan-Kettering Cancer Center (United States)

Kestutis Sutkus, The City College of New York (United States)

Sebastian Wachsmann-Hogiu, NSF Center for Biophotonics Science and Technology (United States)

Siavash Yazdanfar, GE Global Research (United States)

Session Chairs

1 Light Scattering Methods

Israel Gannot, Tel Aviv University (Israel)

2 Microscopy Methods

Stavros G. Demos, Lawrence Livermore National Laboratory (United States)

3 Raman Scattering Methods

Zhiwei Huang, National University of Singapore (Singapore) 
4 Fluorescence Methods

Wubao Wang, The City College of New York (United States)

Yang Pu, The City College of New York (United States)

5 Novel Methods and Instrumentation I

Anna N. Yaroslavsky, University of Massachusetts Lowell (United States)

6 Novel Methods and Instrumentation II

Stavros G. Demos, Lawrence Livermore National Laboratory (United States)

7 Anniversary Session: 45 Years of Supercontinuum Generation Robert A. Fisher, RA Fisher Associates, LLC (United States)

Robert W. Boyd, University of Ottawa (Canada) 


\section{Introduction}

The conference "Optical Biopsy XII," part of the SPIE Photonics West BiOS symposium, was held on February 4-5, 2014 in San Francisco. The conference consisted of seven oral sessions and hosted 33 papers with 21 of these from international contributions and four posters. In addition, the program included a special session entitled "45 Years of Supercontinuum Generation" consisting of seven invited presentations by world experts and pioneers to give an overview on the field of supercontinuum. The new non planar twisted form of light with orbital angular momentum and polarization was reviewed. We hypothesize that this method may provide a new tool for probing the structure and status of tissues. The slides from the "Ultimate ultrafast white light's first observations: early discovery circa 1970" presentation can be found in this volume.

As in previous years, the quality of the presentations was very high and included the presentation of novel approaches as well as the most recent developments in well established methods. Most presentations were concentrated in three main thematic areas: a) Light scattering; Tissue diagnosis with optical spectroscopy and spectral imaging; microscopy methods, Raman, and native fluorescence (auto-fluorescence). b) Imaging at the cell level for pathological assessment; scattering of complex structure light. c) Novel instrumentation and techniques for in vivo diagnosis.

Major advances in biomedical optics have been presented on: Tryptophan as a key cancer marker in aggressive cancers; enhancing the penetration depth in two photon microscopy using the second singlet state S2 of contrast agents in brain tissue so both the exciting and emission wavelengths are in therapeutic window; introduction of Resonance Raman in brain cancer; and the introduction of a $3 \mathrm{rd}$ optical window at $1650 \mathrm{~nm}$ to $1800 \mathrm{~nm}$ in tissue to reduce scattering and blurring effects in tissues.

It was worth noting that for another year there was a contribution on the detection of disease using optical spectroscopy signatures of body fluids such as urine or blood plasma. As the field of metabolomics continues to grow, it is possible that "optical metabolomics" may be a future growth area in the field of optical biopsy. The trend of increasing focus on translational research that was observed in previous years continued this year with nearly all speakers using part of their time to explain how the method and results presented can be implemented in a clinical setting. This trend is expected to continue as the field continues to mature and the medical community starts recognizing that some of these techniques will be a major part of medical practice in the near future.

We wish to thank Hamamatsu Corporation, Energy Research Company, Bay Spec, Inc., PerkinElmer Inc., and Intuitive Surgical, Inc. for support of Optics Biopsy 
sessions, and Coherent Inc., LEUKOS, Corning Inc., NKT Photonics A/S, Fianium Ltd. and ThorsLabs, Inc. for support of the Supercontinuum session. We also thank the help of the session chairs, program chairs and SPIE staff for their help in making this successful conference.

Robert R. Alfano Stavros G. Demos 


\section{ANNIVERSARY SESSION: 45 YEARS OF SUPERCONTINUUM GENERATION ABSTRACTS}

Ultimate ultrafast white light's first observations: early discovery circa 1970 [8940-32], Author(s): Robert R. Alfano, The City College of New York (USA)

Abstract: The first discovery and mechanism of super continuum generation with ultrashort pulses in solids (glasses and crystals) and rare gas media will be presented. How the observation of the white light over $6000 \mathrm{~cm}-1$ was unraveled for the first time with excitation of ultrashort pulses 45 years ago.

Evolution of the supercontinuum source [8940-33]

Author(s): James Roy Taylor, Imperial College London (United Kingdom)

Abstract: Spectral broadening and the generation of new frequencies were initially observed in pulsed laser systems in the mid-1960s as an inherent feature of the uncontrollable nonlinear process such as selffocusing and self-phase modulation occurring primarily in the gain media and were looked upon as deleterious rather than a resource. With the advent of mode locked lasers to generate picosecond pulses new effects were observed. Developed by the Alfano group in bulk media external to the laser in the 1970s the supercontinuum or "white light" source has now evolved into a commercially successful and highly compact source that can readily extend over more than three octaves with spectral power densities exceeding $100 \mathrm{~mW} / \mathrm{nm}$. In this presentation I will describe this remarkable evolution.

Supercontinuum generation in optical fibers and its biomedical applications [8940-34] Author(s): Govind P. Agrawal, Univ. of Rochester (USA)

Abstract: A microstructured optical fiber was first used in 2000 for supercontinuum generation. Since then, enormous progress has been made in understanding, controlling, and marketing fiber-based supercontinuum sources. In particular, biomedical applications of such sources are revolutionizing the field of medical imaging. In this talk I review the recent progress in this area and describe how a supercontinuum can be employed for biomedical imaging using the techniques known as coherent antiStokes Raman scattering, stimulated emission-depletion microscopy, and optical coherence tomography.

White light for the fast lane: supercontinuum generation in all-normal dispersion fibers for ultrafast photonics [8940-35]

Author(s): Alexander M. Heidt, Univ. of Southampton (United Kingdom)

Abstract: This talk will give an overview of the unique properties of supercontinuum generation (SCG) in allnormal dispersion (ANDi) fibers pumped by ultrashort pulses and the possibilities they offer for ultrafast photonics applications. In contrast to their anomalously pumped counterparts, the SCG process in ANDi fibers conserves a single ultrashort pulse in the time domain, completely suppresses soliton formation and decay, and avoids noise-amplifying nonlinear dynamics. The resulting spectra combine the best of both worlds - the broad, more than octave-spanning bandwidths usually associated with anomalous dispersion pumping with the high temporal coherence, pulse-to-pulse stability and well-defined temporal pulse characteristics known from the normal dispersion regime.

These characteristics are ideally suited for ultrafast photonics, and I will present application examples including the generation of high quality single-cycle pulses and their amplification, as well as ultrafast spectroscopy. This talk will also explore the exciting new possibilities enabled by extending this approach into the mid-IR spectral region using novel soft glass fiber designs. 


\section{Supercontinuum generation in microstructure fiber at the advent of femtosecond combs}

[8940-36]

Author(s): Steven T. Cundiff, JILA (USA)

Abstract: The development of frequency combs based on femtosecond lasers revolutionized optical frequency metrology, enable optical atomic clocks and is essential to the production of atto-second pulses.

Frequency combs are produced by locking the offset frequency of the laser, which in turn is most easily done if the spectrum spans an octave. Supercontinuum generation in microstructure fiber can easily span an octave, even for the nanojoule pulses produced by a mode-locked laser, while preserving coherence, and thus the comb spectrum.

\section{Collapsing light really shines [8940-37]}

Author(s): Alexander L. Gaeta, Cornell Univ. (USA)

Abstract: The history of super continuum generation with ultrashort pulses in bulk media will be reviewed. In particular, a description on how the self-focusing dynamics leads to shock formation and the generation of extremely broad spectra when an ultrashort pulse travels through a transparent gas, liquid, or solid.

Cross-phase modulation in optical Kerr media: from early discovery works to recent alloptical applications [8940-38]

Author(s): Patrice L. Baldeck, Univ. Joseph Fourier (France)

Abstract: Kerr cross-phase modulation (XPM) occurs when optical waves co-propagate in instantaneous intensity-dependent media. This all-optical effect leads not only to phase changes, but also to frequency, amplitude and spatial effects. In 1986, the first experiment reported the spectral broadening of a probe pulse by a pump pulse. Subsequent experiments demonstrated optically-induced phenomena, such as frequency shift, amplitude modulation, and spatial focusing that have been investigated in thousands of publications during the last two decades. 


\title{
SPIE Photonics West Anniversary Session: 45 Years of Supercontinuum Generation \\ San Francisco, Wednesday 5, February 2014
}

\section{Thanks for the support of this symposium by companies that market Supercontinuum sources:}

\author{
Leukos \\ Coherent \\ Fianium \\ Corning \\ Thorlabs \\ NKT Photonics Inc.
}

\section{Ultimate ultrafast white light's first observations: early discovery circa 1970}

\section{Robert R. Alfano \\ Distinguished Professor of Science and Engineering \\ The City College of New York}


Today I will discuss an elegant and most colorful phenomena of generating

\section{The Ultimate White Light}

discovered in 1969, about 45 years ago and still going strong for various applications in biology, metrology, condensed matter, chemistry, and now in biomedicine.

This discovery was made from the knowledge from many Giants in science.

\section{Peaceful Scene in Nature}

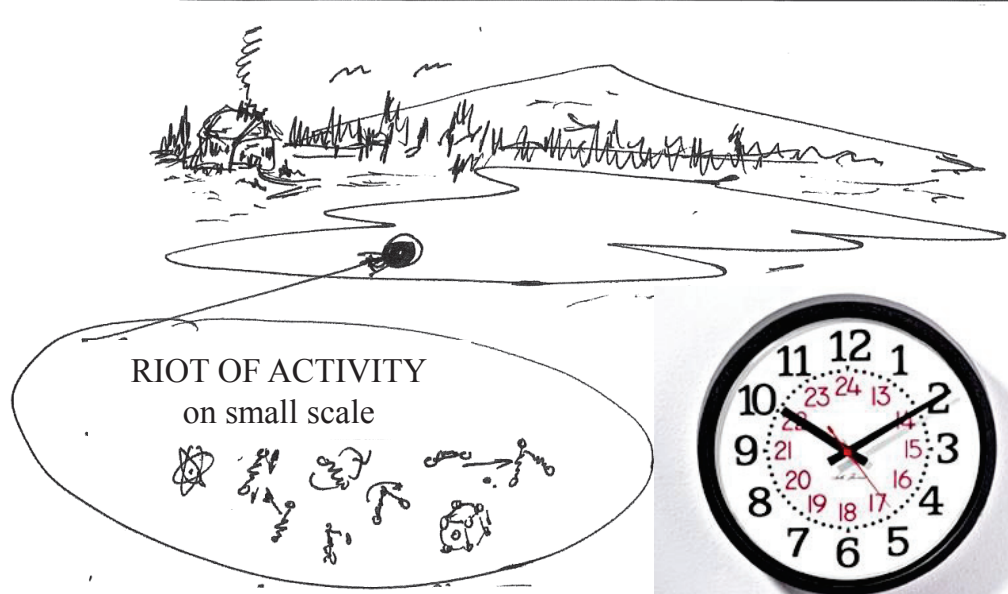

RIOT OF ACTIVITY

Need a clock with time scale of the molecular, atomic, electronic world - to probe fundamental processes in nature - laser pulse - (ps, fs, as) 


\section{Salient Properties of Light}

- Wavelength (color)

- Time

- Polarization

- Coherence

- Wave fronts plane, helical, spiral

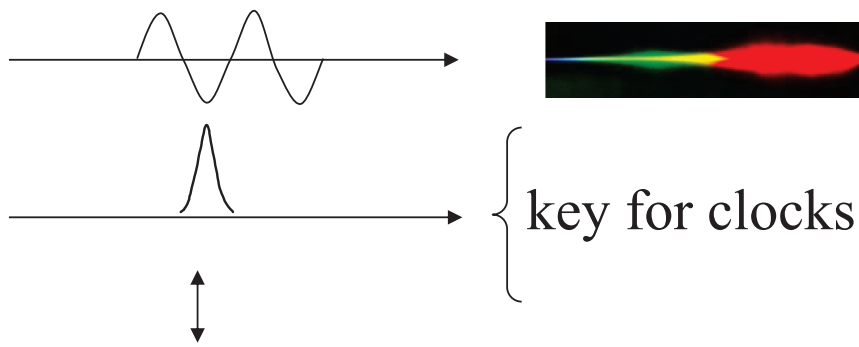

Processes
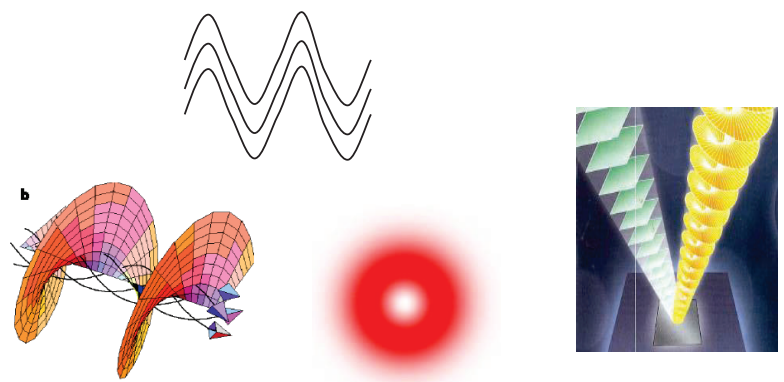

- Emitted - fluorescence spectroscopy

- Absorbed - excitation spectroscopy

- Scattered-Raman and elastic

\section{Laser light and Supercontinuum}

Typical laser light beam has narrow spectral band:

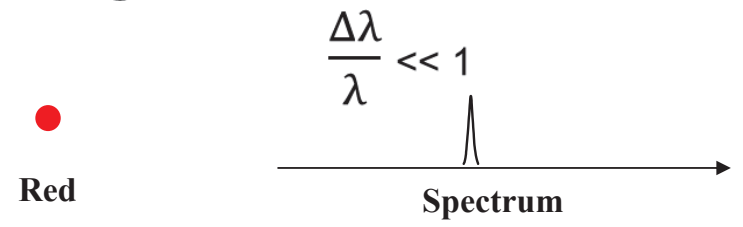

Supercontinuum light is white light:

$$
\frac{\Delta \lambda}{\lambda} \sim 1
$$

White

Violet

Spectrum

NIR

arises from nonlinear optical effects from the third $\left(X_{3}\right)$ and second $\left(X_{2}\right)$ order susceptibilities $\left(n_{2}\right.$, SRS, 4WM) using short $p s$ and fs laser pulses via polarization (dipole moment/volume):

$$
P=\chi_{\text {Nonlinear optical processes }}^{\chi_{1} \mathrm{E}+\chi_{2} \mathrm{E}^{2}+\chi_{3} \mathrm{E}^{3}+\ldots} \cdot \begin{gathered}
\mathrm{E}-\text { electric field } \\
\chi_{3} \rightarrow \mathrm{n}_{2}(\mathrm{t}) \rightarrow \Phi(\mathrm{t}) \text { - phase }
\end{gathered}
$$




\section{Brief History Behind Supercontinuum}

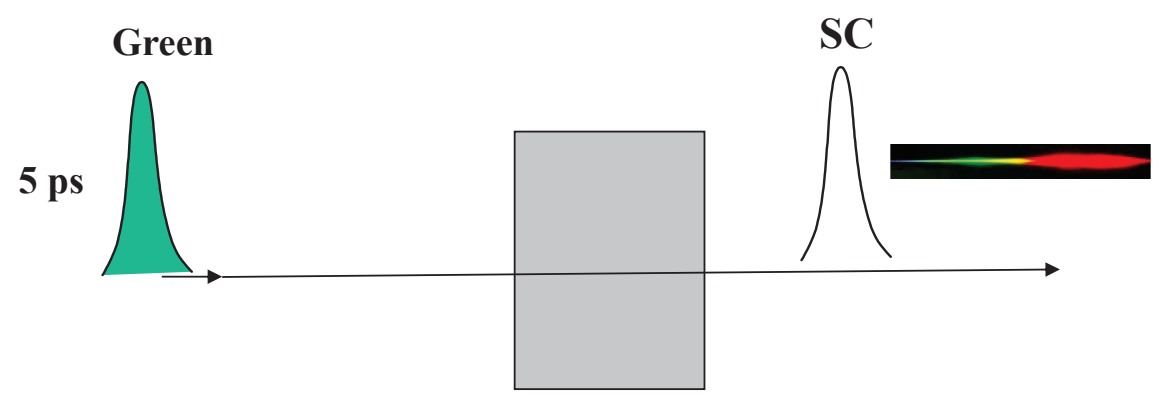

Three seminal PRL Papers in 1970, Vol. 24 (Alfano and Shapiro):

$\mathrm{SC}$ in solids (glasses, crystals)

$\mathrm{SC}$ in rare gas liquids (Ar, $\mathrm{Kr}$ ) and solid $\mathrm{Kr}$

- observation of SPM, PRL 24, 592, (1970),

- observation of 4WM, PRL 24, 584, (1970),

- underlying mechanisms due to electronic clouds, PRL 24, 1217 (1970), for $\mathbf{n}_{2}$

45 years has passed

\section{Brief SC history}

Early 1969 - Alfano and Shapiro teamed up at GTE Lab, Bayside, NY

GTE

Verizon

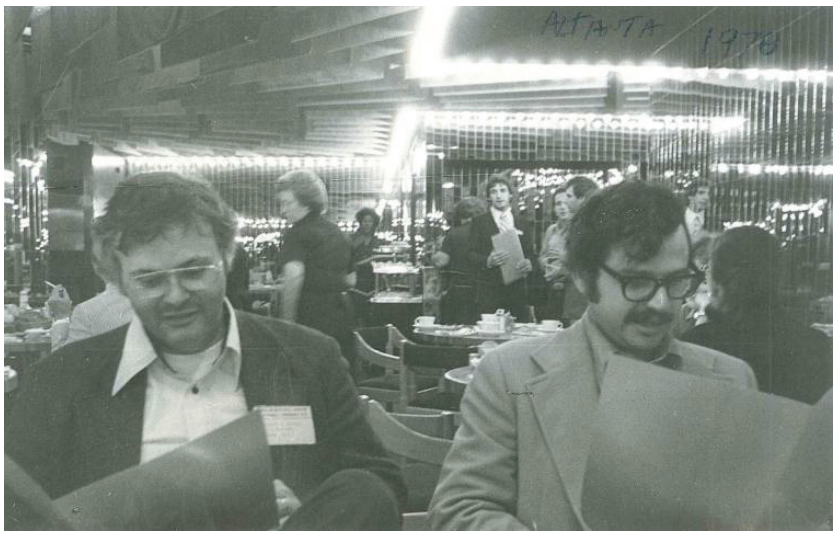

1969 - Alfano and Shapiro observed the light continuum from $400 \mathrm{~nm}$ to $7000 \mathrm{~nm}$ in glass (optical phonons in solids, daughter vibrations...) 


\section{From 1970 Physics Review Letters: Alfano and Shapiro}

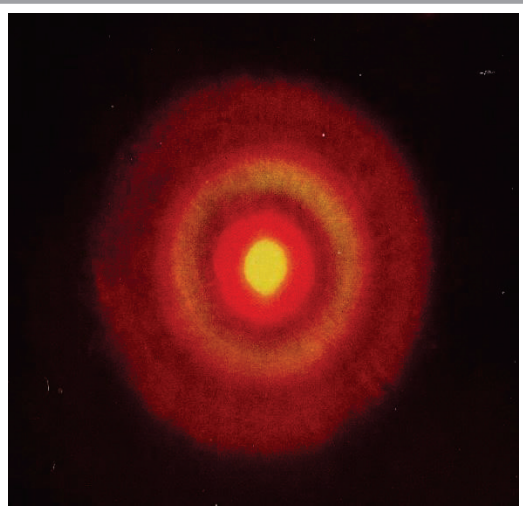

Pattern of 5 ps green light pulse after it passes transparent piece of glass

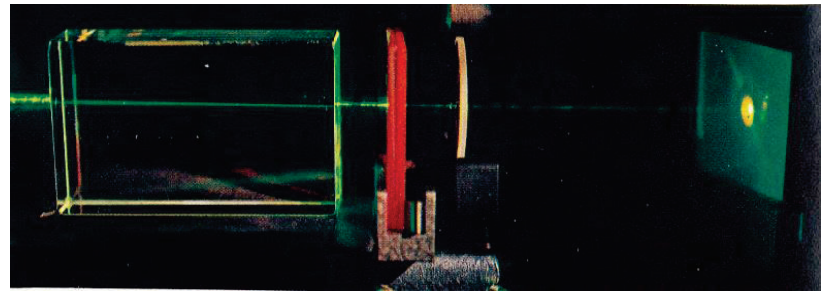

\section{GTE Picosecond Lab Photos ( 1969)}
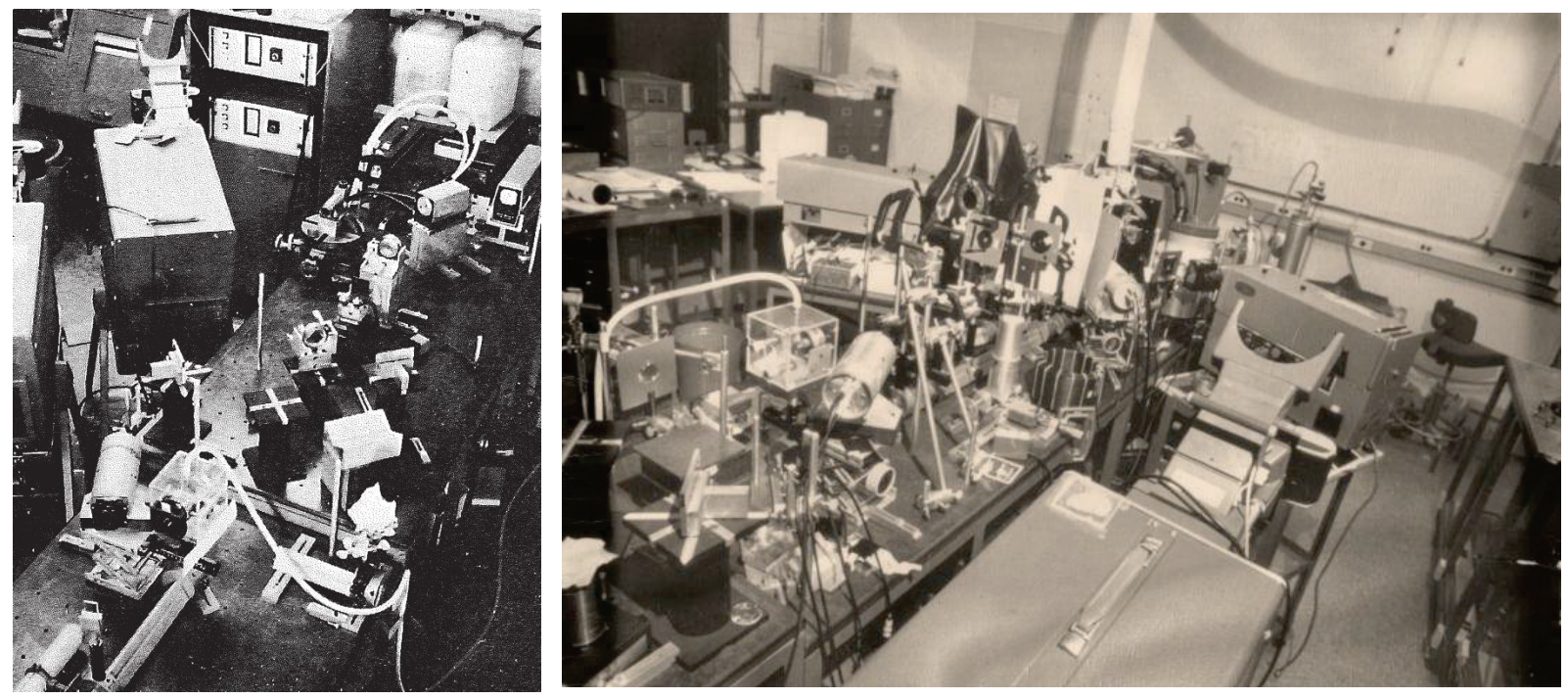


\section{Brief History of Supercontinuum}

\section{Ultimate White Light}

Solids (glasses, crystals)

Rare gas liquids ( $\mathrm{Ar}, \mathrm{Kr}$ ) and solid $\mathrm{Kr}$

Liquids

Semiconductors

Gases

Fibers

Optical vortex
1969; PRL 24, 584, 592 (1970), Alfano and Shapiro 1970; PRL 24, 1217 (1970), Alfano and Shapiro 1972; Opt. Commun. 4, 413 (1972), Werncke et. al. 1985; Opt. Lett. 10, 624 (1985), Corkum et. al. 1986; PRL 57, 2268 (1986), Corkum et. al. 2000; Opt. Lett. 25, 25 (2000), Ranka et. al. 2006; Opt. Lett. 31, 2725-2727 (2006), Sztul et. al.

\section{Publications on Supercontinuum in Scientific Literature}

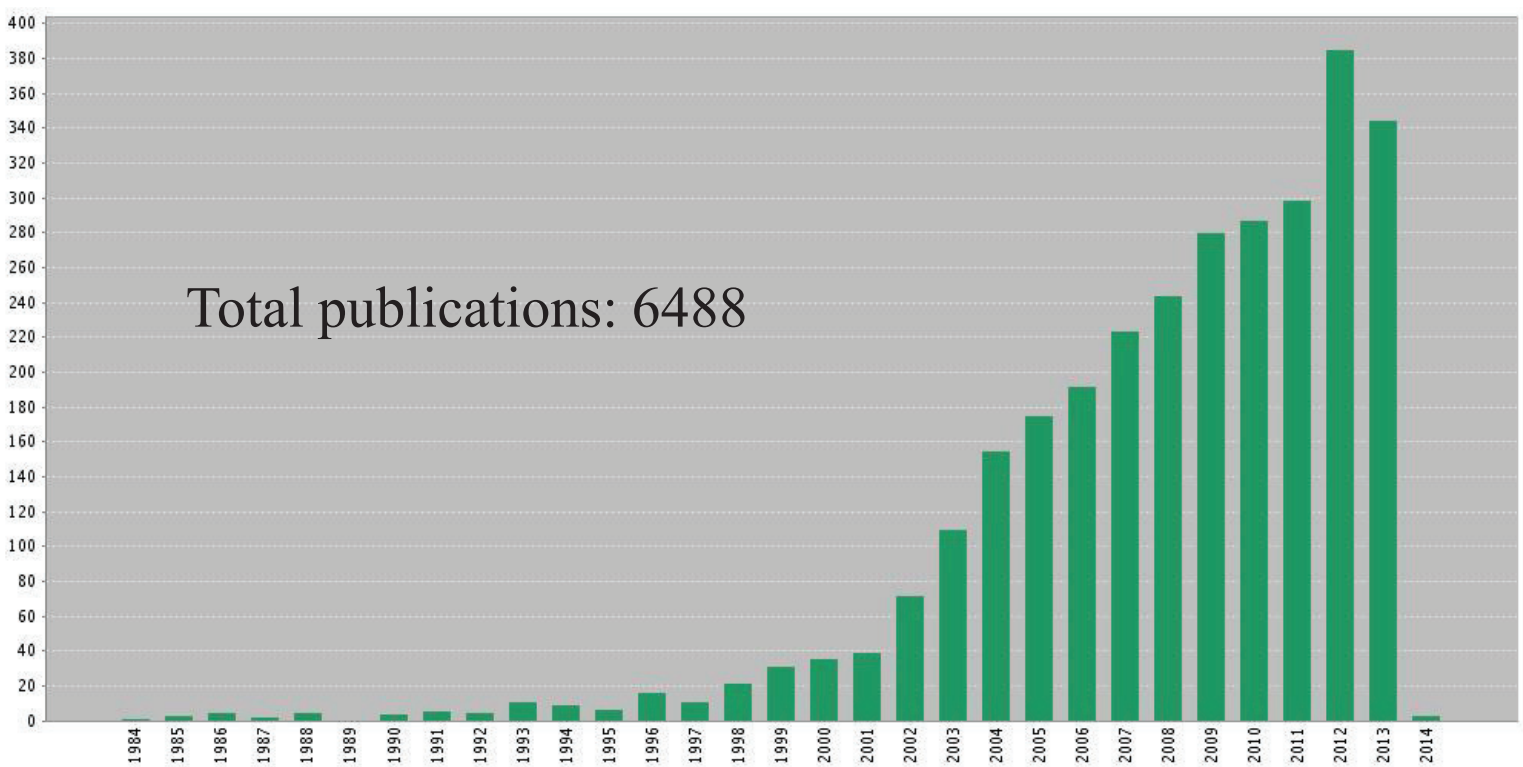




\section{Citations of Articles on Supercontinuum}

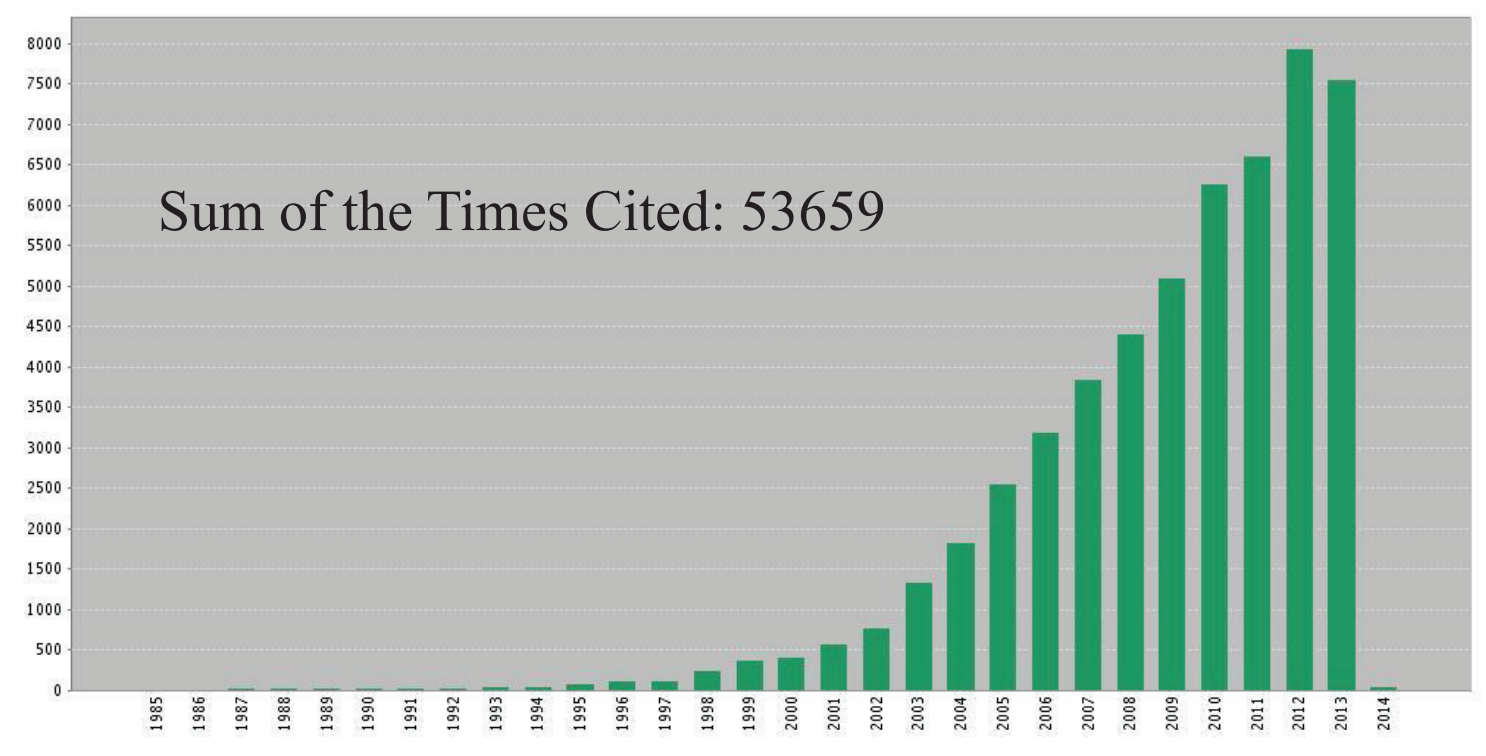

\section{Current day SC from special holey fiber}

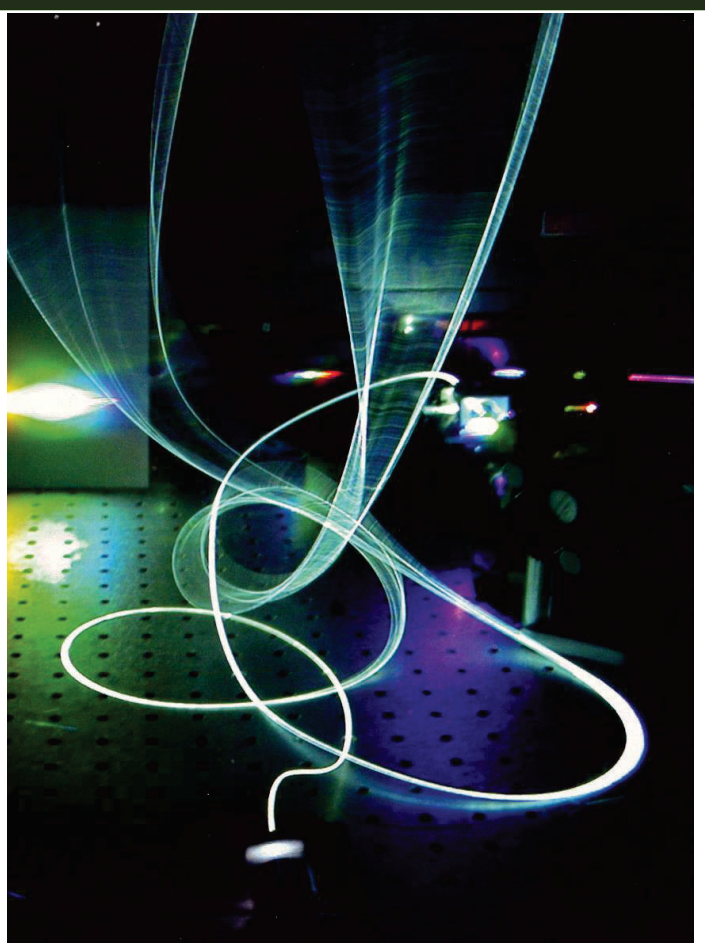




\section{Current day SC from bulk material}

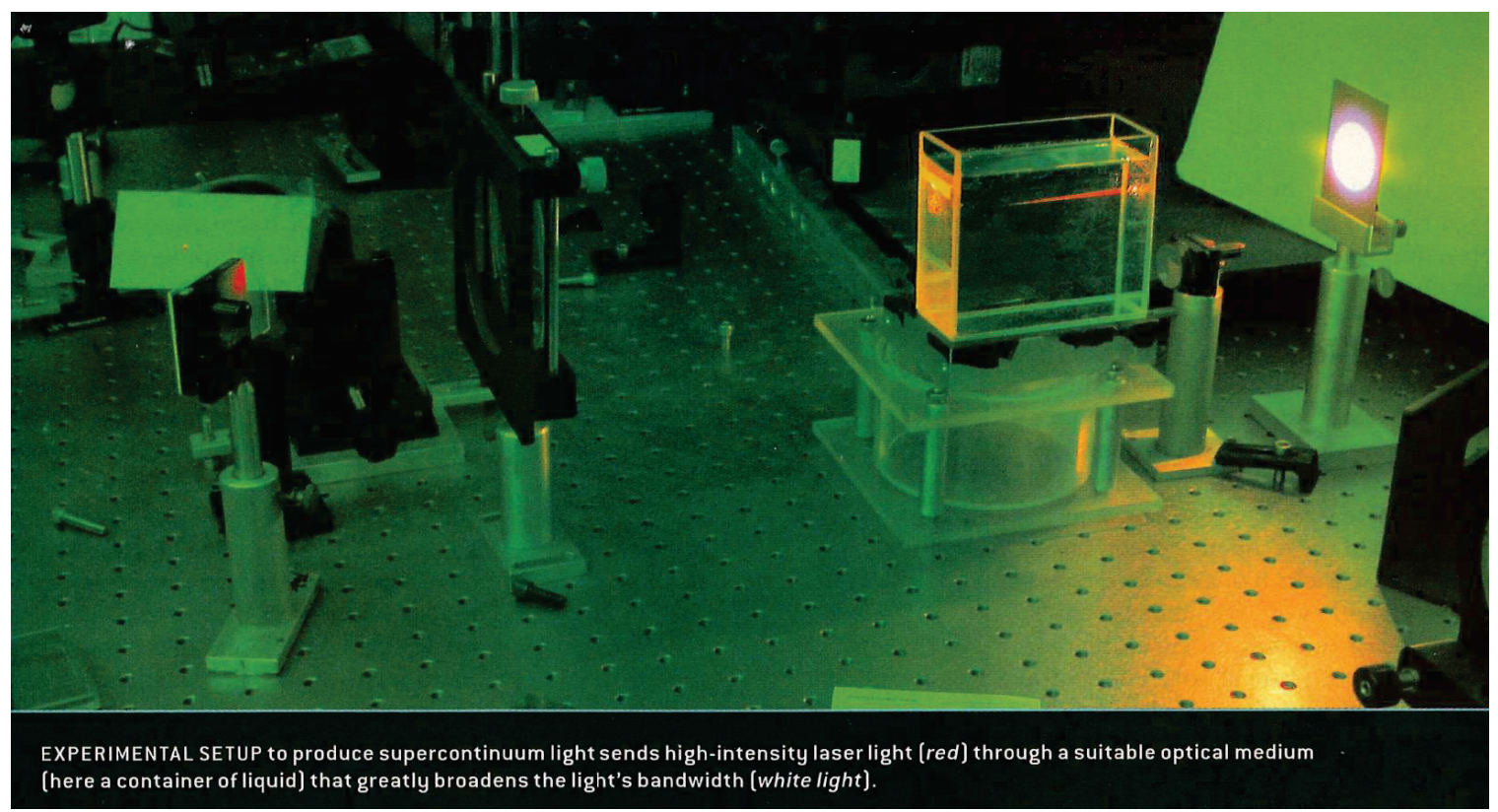

\section{Ultrafast Optical Clocks}
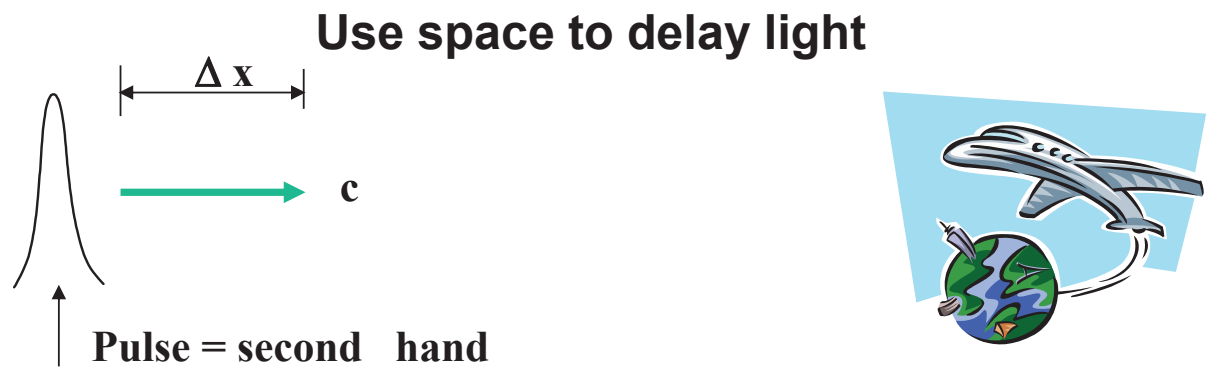

$$
\begin{array}{ccl}
\Delta x=v \Delta t & \text { For } \Delta x=1 \mathrm{~mm} & \text { For } \Delta x=100 \mu \mathrm{m} \\
\Delta t=3 \mathrm{ps} & \Delta t=300 \mathrm{fs}
\end{array}
$$

Mechanisms for optical clocks:

- prism

- grating

- array of mirrors

- streak camera

- NLO gates

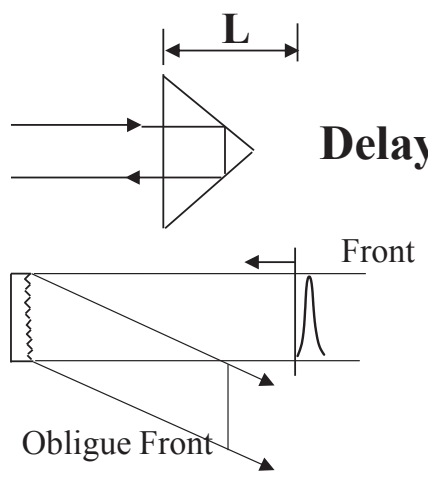




\section{SC - Supercontinuum - SPM underlying processes}

Phase:

$$
\phi(\omega, \mathrm{t})=\omega_{\mathrm{L}} \mathrm{t}-\mathrm{n} \omega \mathrm{z} / \mathrm{c}
$$

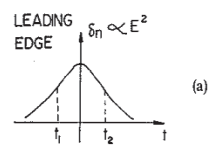

Index of refraction:

SPM

$$
n=n_{0}+n_{2} E^{2}(t)+\ldots
$$

$\phi(\omega, \mathrm{t})=\omega_{\mathrm{L}} \mathrm{t}-\left(\mathrm{n}_{0}+\mathrm{n}_{2} \mathrm{E}^{2}(\mathrm{t})\right) \omega \mathrm{z} / \mathrm{c}$

$\underline{\mathrm{SC}}$

$\Omega=\partial \phi / \partial \mathrm{t}=$ new frequencies

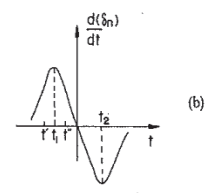

$$
\Omega=\omega_{\mathrm{L}}-\underbrace{-\underline{\mathrm{n}}_{2} \omega \mathrm{Z}}_{\partial \mathrm{n} / \partial \mathrm{t}} \frac{\partial \mathrm{E}^{2}(\mathrm{t})}{\partial \mathrm{t}}
$$

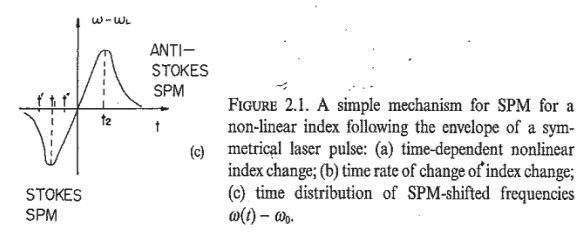

$$
\Delta \Omega \sim \frac{n_{2} I z}{\tau_{p}}
$$

\section{Main Supercontinuum Mechanisms: $\mathbf{n}_{\mathbf{2}}$}

SPM - Self Phase Modulation (real $\left.\chi_{3}\right): \Delta \mathbf{n}=\mathbf{n}_{2} I(t)$

FWM - Four Wave Mixing (real $\left.\chi_{3}\right): \omega_{1}+\omega_{2} \rightarrow \omega_{3}+\omega_{4}$

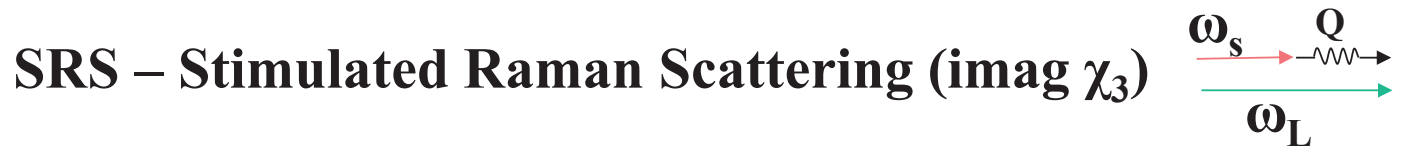

XPM - Cross Phase Modulation: $\Delta n\left(\omega_{1}\right)=n_{2}\left(I_{1}+2 I_{2}\right)$

SS - Self Steepening

\section{Ionization}

Avalanche

Solitons - Fission, Raman shift, Dispersion, Roque waves (interplay between SPM (+) and GVD anomalous (-)) 


\section{Supercontinuum generation}

\section{Ultimate White Light}

From: X-rays, UV, Visible, NIR, IR

Nonlinear part of index of refraction: $\mathrm{n} \longrightarrow \mathrm{n}_{2}$

Mechanism: $\mathrm{n}_{2}=$ electronic, vibration, rocking, orientation, translation

Response

Time:

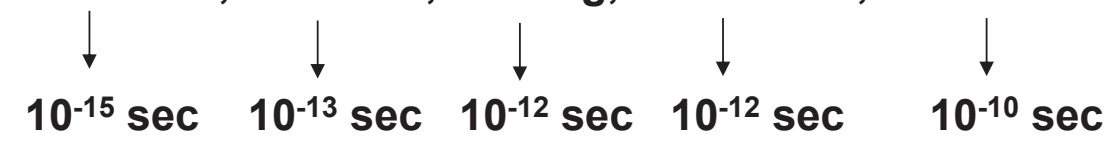

$\mathrm{n}_{2}$ (electronic) $\longrightarrow$ attosecond pulses

\section{Major advance - fibers for compact SC source}

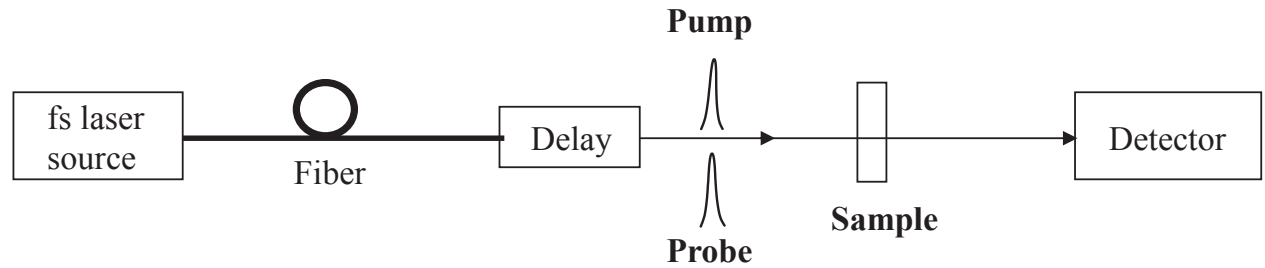

Holey fibers - photonic crystal fibers

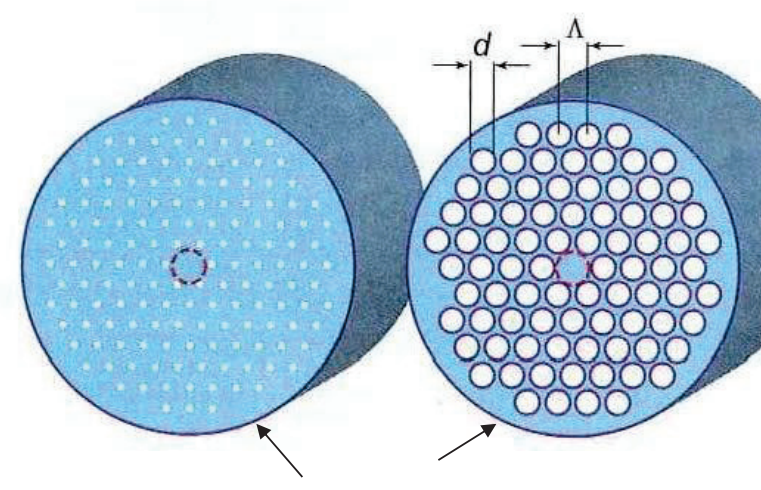

Solid core

Air holes

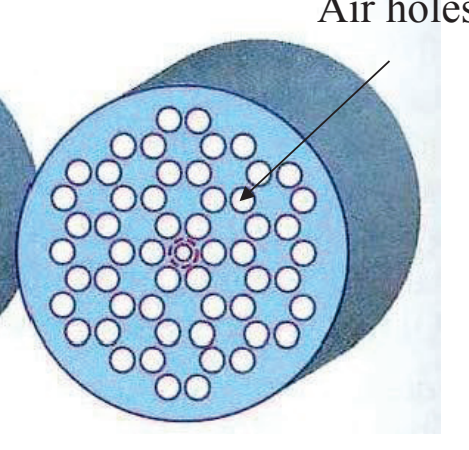

Air core 


\section{Supercontinuum (SC)}

\section{Ultimate White Light}

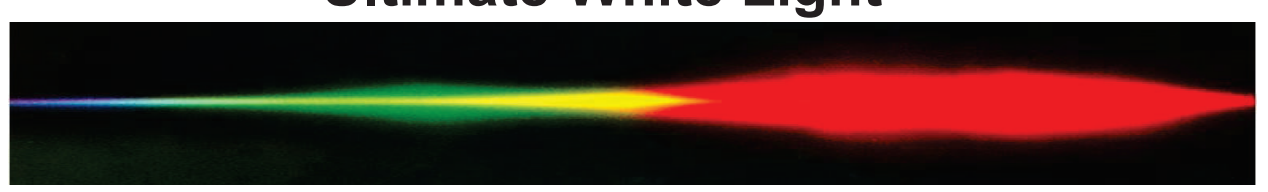

Spans: $400 \mathrm{~nm}$ to $1400 \mathrm{~nm}$

Energy: $1 \mathrm{~mJ}$; pulse < 1 ps

Spectral energy brightness: $1 \mathrm{~mJ} / 1000 \mathrm{~nm}=\mu \mathrm{J} / \mathrm{nm}$

Focus to $100 \mu \mathrm{m}$ gives $10 \mathrm{~mJ} / \mathrm{nmcm}^{2}$

Spectral power brightness:

$10 \mathrm{~mJ} / \mathrm{nmcm}^{2} \mathrm{ps}=10 \times 10^{9} \mathrm{~W} / \mathrm{nmcm}^{2}=10 \mathrm{GW} / \mathrm{nmcm}^{2}$

$\mathrm{SC}$ average $100 \mathrm{~mW} / \mathrm{mm}^{2}=10 \mathrm{~W} / \mathrm{cm}^{2}$;

Sun $-0.14 \mathrm{~W} / \mathrm{cm}^{2}$

SC UV using fibers $300 \mathrm{~nm}$ (aim)

Now, SC $200 \mathrm{eV}$ enters $\mathrm{x}$-rays in Argon gas using $16 \mathrm{~mJ}, 800$ $\mathrm{nm}, 60 \mathrm{fs}$ pulses

Commercially available fs lasers:

1 W, 10nJ, oscillator@100 MHz; 1mJ amplifier@1kHz;

2.5 W, $10 \mu \mathrm{J}$ amplifier@250kHz

\section{Enabling SC Applications}

\section{Ultimate White Light}

\section{Enabling SC applications:}

- accurate clocks $\longrightarrow$ Nobel prize (2006)

- chemistry/biology $\longrightarrow$ Nobel prize (1999)

- communication

- NLO

- biological and medical - OCT

- nm microscopy

- as laser pulse

- optical vortex beams 


\section{Next Medical Advances - Use of Supercontinuum in Biomedicine}

Supercontinuum applications in biomedicine is in its infancy

- $\quad$ Therapy (SC room)

- Wound healing

- NLO in tissue (proteins imaging)

- Ultra microscopes

- OCT

- Neuroscience

Fiber

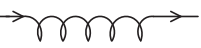

SC Chamber

fs. Laser Pulses

fs. Laser System
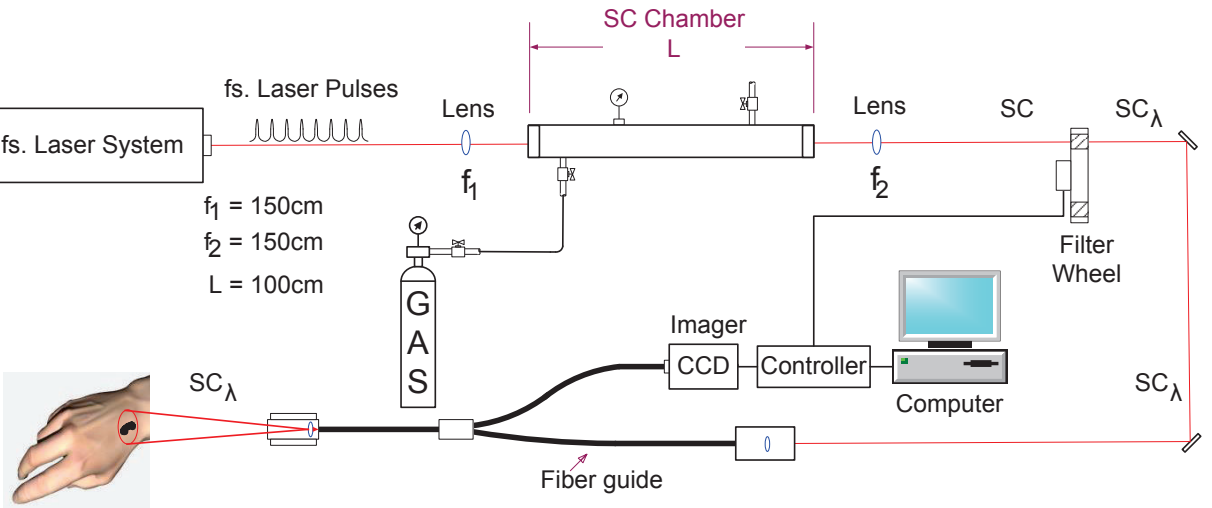

Wound / cut

Fiber guide

\section{Closing}

SC use: - in biomedical optics, biomedicine

- in communication with OAM and spatial modes (pentabits/sec, terabits/sec)

Hyper-photon: SC + OAM + vector beam(polarization) + spatial modes

Zeptosecond pulses 